\title{
Modernidade, globalização e fé
}

\author{
Modernity, globalization and Faith
}

Marcelo Amaral Lanfranchi

\section{Resumo}

Este estudo analisa as mudanças econômicas e culturais, em uma sociedade onde a fé parece ter sido abandonada, dando lugar a variadas tentativas de resposta frente à modernidade e à globalização. $\mathrm{O}$ mundo passou a ser um só país, com línguas, tradições e costumes diferentes, fazendo com que tomemos contato com diversas maneiras de pensar e agir. Essa diversidade tem estimulado conflitos sociais, em grande parte devido à intolerância em relação ao diferente. A intolerância religiosa tem sido uma das maiores causas de conflito, matando milhares de pessoas anualmente e provocando o deslocamento de outros milhares em busca de socorro, não somente procurando uma melhor qualidade vida, mas também lutando por sobrevivência. Essa migração em busca de qualidade de vida melhor vem sendo um grande problema para vários países. Além do problema econômico causado pelo aumento populacional, há também um grave problema social: o conflito cultural. A Igreja Católica que já teve grande influência no mundo europeu, pretende ser não só a voz dos católicos, mas de toda a população, como defensora dos direitos da pessoa humana e contrária à intolerância, alertando o mundo sobre os perigos sociais e econômicos da globalização.

Palavras-chave: Globalização. Modernidade. Religiosidade.

\begin{abstract}
This study analyzes the economic and cultural changes in a society where faith seems to have been abandoned, giving way to various attempts to respond to modernity and globalization. The world became a single country, with different languages, traditions and customs, making us come into contact with different ways of thinking and acting. This diversity has fueled social conflicts,
\end{abstract}


largely due to intolerance towards the different. Religious intolerance has been one of the biggest causes of conflict, killing thousands of people annually and causing thousands more to be displaced in search of relief, not only seeking a better quality of life, but also fighting for survival. This migration in search of a better quality of life has been a major problem for several countries. In addition to the economic problem caused by the population increase, there is also a serious social problem: cultural conflict. The Catholic Church, which has had great influence in the European world, intends to be not only the voice of Catholics, but of the entire population, as a defender of human rights and against intolerance, warning the world about the social and economic dangers of globalization.

Keywords: Globalization. Modernity. Religiosity.

\section{Introdução}

Nos últimos séculos, com uma procura cada vez maior de respostas para a vida e seus mistérios fora das religiões e tradições culturais, buscou-se refúgio na ciência e em ideologias políticas, econômicas e de mercado. A ideia de religião parecia ultrapassada e suas tradições inúteis na busca por uma sociedade melhor. Tradições religiosas, familiares e culturais foram deixando de ser conceitos vividos por uma comunidade para serem agora conceitos privados, de foro íntimo. Além disso, os meios de comunicação, cada vez mais eficientes, foram aproximando pessoas e culturas, mostrando realidades desconhecidas ou não imaginadas por muitas sociedades antes isoladas. Surgem assim sistemas sociais, políticos e familiares completamente estranhos para certos grupos da população mundial. De certa forma, pode-se afirmar que esse conhecimento é benéfico, pois dele podem partir convergências e ideias para uma melhor convivência entre povos distintos com diversas culturas e estruturas sociais. Por outro lado, a experiência com o desconhecido pode trazer introspecção, isolamento e até agressividade como forma de defesa contra a "decadência, impureza e descontrole" da sociedade mundial, além de pobreza, fome e conflitos sociais. Sem as tradições religiosas, muitos povos perdem sua identidade e se fecham procurando uma espiritualidade individual. Isso tem sido uma preocupação de várias confissões religiosas e dentre elas a Igreja Católica, que tem procurado se atualizar e se ajustar a esse novo mundo, levando a sua voz não somente à comunidade católica, mas também a toda a população mundial. 


\section{Globalização e modernidade}

A procura por uma maior e melhor comunicação entre povos distantes sempre foi desejada, principalmente por mercadores e culturas determinadas à exploração e à conquista. A busca por matéria prima ou manufaturados, comida e especiarias era o desejo de muitos povos que viviam separados, isolados ou com escassez de produtos essenciais à sua sobrevivência e bem-estar. Essa busca constante foi um desejo e uma aventura durante muitos séculos. Grandes nações e impérios com o objetivo de conquistar, enriquecer ou ter garantidos seus suprimentos, também se lançaram em busca de novas terras e civilizações. Como resultado positivo houve muitas vezes troca de conhecimentos técnicos e culturais, gerando novos costumes, adotados ou adaptados por parte dos povos estrangeiros e também dos nativos. Toda essa troca de conhecimentos regularmente gerava maior prosperidade e sabedoria. Em contrapartida, não raramente os grandes impérios subjugavam as sociedades conquistadas, impondo sua própria cultura considerada melhor e mais desenvolvida. E as tradições culturais dos povos conquistados eram tidas como primitivas, subdesenvolvidas. Nesse sentido, a globalização praticada por povos conquistadores nada mais era do que imposição cultural, com consequente perda da identidade da população conquistada.

Tentativas de "globalização" já foram praticadas na antiguidade, geralmente com a uniformização de povos de regiões distintas, formando grandes impérios organizados politicamente sob o governo de um grande imperador. Alexandre o Grande (século IV a.C.), por exemplo, construiu seu império respeitando as tradições culturais dos povos conquistados, sem grande prejuízo de sua identidade social e cultural. Também o Império Romano, que teve seu auge territorial por volta de 180 d.C. e dominou boa parte da Europa, norte da África e Oriente Médio, impôs suas leis e costumes, mas permitiu que as regiões conquistadas também preservassem sua cultura, com a condição de nunca se oporem à cultura romana.

Esse desejo de troca e conquista se manteve por toda a história mundial, criando e destruindo impérios, modificando culturas e permitindo novas descobertas.

Porém, desde o último século, a tecnologia vem se desenvolvendo em tal velocidade, que tem aproximado cada vez mais os povos do mundo inteiro, facilitando esse desejo de troca de produtos, tecnologia e cultura.

Devido à velocidade e qualidade da tecnologia da informação e da mídia, o planeta todo está interconectado, possibilitando que um habitante da uma longínqua e isolada região tome conhecimento de um fato ou se comunique 
com pessoas a milhares de quilômetros de distância imediatamente. A internet dá a sensação de simultaneidade, tudo acontece ao mesmo tempo e é transmitido "em tempo real" para o mundo todo. Assim, quem muda são o espaço e o tempo, diminuem as distâncias e não há mais espaços isolados. Aumentam-se as relações políticas, econômicas, sociais e religiosas entre os mais variados povos do planeta, influenciando-se mutuamente e gerando conhecimento e prosperidade. E com a formação de novos mercados e empresas transnacionais, esse processo se tornou irreversível, impondo por vezes, não apenas uma "superioridade" econômica, mas também política e cultural, criando enormes conflitos.

Assim, segundo Giddens:

A globalização pode assim ser definida como a intensificação das relações sociais em escala mundial, que ligam localidades distantes de tal maneira que acontecimentos locais são modelados por eventos ocorrendo a muitas milhas de distância e vice-versa. Este é um processo dialético porque tais acontecimentos locais podem se deslocar numa direção inversa às relações muito distanciadas que os modelam. A transformação local é tanto uma parte da globalização quanto a extensão lateral das conexões sociais através do tempo e do espaço. Assim, quem quer que estude as cidades hoje em dia, em qualquer parte do mundo, está ciente de que o que ocorre numa vizinhança local tende a ser influenciado por fatores - tais como dinheiro mundial e mercados de bens - operando a uma distância indefinida da vizinhança em questão. ${ }^{1}$

Essa globalização junto à modernidade tende a padronizar certas características, sobretudo, políticas e econômicas, em nome das boas relações comerciais. Porém, nem sempre essa padronização é possível, aceitável ou benéfica para ambos os envolvidos. As negociações comerciais reduzem o sujeito e a pequena empresa a concorrentes, nem sempre com poderio para competir com conglomerados internacionais, levando certas regiões à pobreza, principalmente naquelas regiões que dependem de um único material ou forma de produção. Libânio afirma que,

Mais grave que uma uniformização cultural, a globalização tem exercido papel devastador sobre os países emergentes. Globaliza-se a produção dos bens industriais, do comércio e, sobretudo, do capital financeiro. A globalização da produção tem buscado os lugares onde se pagam os mais

\footnotetext{
${ }^{1}$ GIDDENS, A., As consequências da modernidade, p. 60.
} 
baixos salários para agigantar os lucros. Certos países e grupos humanos, colocados em tal situação de pobreza, acabam aceitando condições aviltantes de trabalho. A globalização do mercado tem destruído indústrias nacionais com aumento do desemprego. E finalmente a globalização financeira joga com o dinheiro, levantando e arruinando em horas até mesmo a economia de um país. E o medo de que isso aconteça tem paralisado economias emergentes. ${ }^{2}$

Assim, a globalização do mercado tem isolado economicamente o "terceiro mundo", causando sérios problemas econômicos e sociais. Além do mais, tem-se sugerido uma desregulamentação ou flexibilização da ordem econômica, concedendo maior liberdade ao capital. Sobre isso, diz Bauman:

A desatada liberdade concedida ao capital e às finanças à custa de todas as outras liberdades, o despedaçamento das redes de segurança socialmente tecidas e societariamente sustentadas, e o repúdio a todas as razões que não econômicas, deram um novo impulso ao implacável processo de polarização, outrora detido (apenas temporariamente, como agora se percebe) pelas estruturas legais do Estado de bem-estar, dos direitos de negociação dos sindicatos, da legislação do trabalho e, numa escala global (embora, neste caso, de modo muito menos convincente), pelos primeiros efeitos dos órgãos internacionalmente encarregados da redistribuição do capital. ${ }^{3}$

O resultado dessa desregulamentação são milhões de desempregados afastados do mercado de trabalho, falta de recursos, isolamento econômico e miséria, com enormes regiões vivendo abaixo da linha de pobreza.

Além disso, a tentativa de eliminação das fronteiras culturais acaba resultando em individualismo e narcisismo, com o enfraquecimento das relações humanas e busca de laços sociais mundiais, sobretudo com o uso da internet. Toda a moral passa a ser relativizada e a identidade outrora ligada a uma cultura específica se vai, e em seu lugar entra a cultura individual, processo no qual se busca a felicidade dentro de um mercado global de possibilidades. Até mesmo a infelicidade deve ser identificada e isolada como modo de combatê-la. Esse processo deve ser individual. Deve o indivíduo encontrar a solução para seu próprio sofrimento. ${ }^{4}$ Assim, com o foco no indivíduo e sem

\footnotetext{
${ }^{2}$ LIBANIO, J. B., Globalização e impacto sobre a fé, p. 9.

${ }^{3}$ BAUMAN, Z., Modernidade e ambivalência, p. 34.

${ }^{4}$ BAUMAN, Z., O mal-estar da pós-modernidade, p. 62.
} 
moral ou ética social, corre-se o risco da perda de identidade, elemento nocivo para a sobrevivência de tradições culturais.

\section{Globalização, religião e fé}

O mundo sempre foi compreendido segundo sua época, espaço e fé. Suas tradições e costumes estavam diretamente ligados à sua fé e de seus antepassados. A cada nova descoberta, a cada fato novo não conhecido ou explicado, temia-se o fim do mundo ou o castigo dos deuses. Fome, escravidão, revoluções e opressões, o homem teve que se reinventar para se adaptar a cada mudança. Da mesma maneira, hoje, com a globalização e a modernidade, os povos têm que se adaptar à sua maneira, para pertencer a essa nova aldeia global.

Neste mundo moderno e globalizado, o discurso sobre Deus, religião e fé contrasta com a verdade do mercado e da sociedade moderna mundial. Sai Deus do centro do mundo e da história e entram o homem e seus conceitos. As referências, as certezas e as grandes respostas são postas em dúvida, certezas de gerações que moldaram sociedades e civilizações são relativizadas. $\mathrm{O}$ certo e o errado, na modernidade, passam a ser grandezas relativas. Isso tudo junto a um mundo que procura respostas não mais em sua fé religiosa, mas no mercado, na política e em concepções ideológicas, que se transformam mais rapidamente do que a capacidade de ser absorvida pela maioria da população mundial. $\mathrm{O}$ papel do indivíduo na família e na sociedade passa também a ser relativizado e conceitos tradicionais são questionados e por muitas vezes negados. Acreditase que o conhecimento, a razão e a tecnologia poderiam substituir tradição, fé e cultura, mas as respostas nessa visão antropocêntrica têm causado mais insegurança e instabilidade do que certezas absolutas. Na visão de Goergen,

Livre da submissão religiosa e guiado unicamente por sua razão, o homem seria o dono de seu destino, imaginava-se. Mal desconfiavam os iniciadores desse programa que essa razão, libertadora das cadeias do autoritarismo, haveria de converter-se ela mesma numa espécie de novo deus cujas divindades menores haveriam de conduzir os homens a uma nova forma de alienação. ${ }^{5}$

É bem verdade que autores como Peter L. Berger (1929-2017) afirmam que a secularização traduz "o processo pelo qual setores da sociedade e da cultura

\footnotetext{
${ }^{5}$ GOERGEN, P., Pós-modernidade, ética e educação, p. 8.
} 
são subtraídos à dominação das instituições e símbolos religiosos". ${ }^{6}$ Porém, essa afirmação faz parte de uma primeira fase de seu entendimento sobre a sociologia da religião. Em um momento posterior, Berger constatou que seu posicionamento se tornara frágil e não se sustentava. Em 2001, o autor afirma:

Ficou cada vez mais evidente que os dados empíricos contradizem a teoria. Com algumas exceções, particularmente a Europa e uma determinada intelectualidade internacional, o nosso mundo não é nada secular; ele é tão religioso como outrora, e em alguns lugares mais ainda. ${ }^{7}$

Não se pode afirmar que a religião deixará de ser uma variável de suma importância na sociedade do século XIX, tendo em vista a influência do neopentecostalismo e do islamismo, ambos alcançando juntos bilhões de fiéis e interferindo diretamente em suas decisões na vida civil.

Alguns líderes religiosos cientes do papel do elemento religioso na sociedade, acreditaram que uma das formas de contornar os eventuais problemas da secularização seria fazer da religião mais um produto, sem necessariamente estar ligado a um determinado povo, região ou cultura. Deste modo, essa religião passaria a ser um acessório, algo privado, como uma mercadoria que serve a um propósito específico. Com objetivo expansionista e ajuda da mídia, esse novo modelo de igreja alcançaria todas as partes do globo, independente da nação ou cultura dos fiéis. Desta maneira não seria necessária ou imprescindível a vida em comunidade e a fé passaria a ser vivida individualmente, independente da cultura ou da tradição. Segundo Prandi:

Ela passa a ser sem fronteiras e sem território, sem ser, contudo, universal e única, como o catolicismo, o protestantismo clássico e o Islão. Depende das forças mercantis da oferta e da procura, devendo adaptar-se a novas situações e novas demandas. Reage às suas concorrentes lançando mão da propaganda e dos meios eletrônicos de comunicação, simplificando sua linguagem em função de um limitado número de "produtos" religiosos cuja propalada eficácia é o atrativo dos neodevotos que arrebata a massa. ${ }^{8}$

Assim, a religião como produto de mercado deveria, ao se expandir, cruzar fronteiras e abandonar tradições regionais, criando uma identidade

\footnotetext{
${ }^{6}$ BERGER, L. P., O dossel sagrado, p. 119.

${ }^{7}$ BERGER, L. P., Os múltiplos altares da modernidade, p. 11.

${ }^{8}$ PRANDI, R., A Religião e o Planeta Global, p. 70.
} 
própria que fugiria aos padrões culturais locais. Essa é a proposta de novas igrejas neopentecostais, com sua teologia da prosperidade, que é baseada na economia de mercado e na sociedade de consumo, se desvinculando de religiões e tradições locais e propondo soluções imediatas para as necessidades dos fiéis. Esse conceito de igreja tem de fato conquistado fiéis em todo o mundo e tem se expandido ano a ano, mas não se apresentou como solução para os conflitos sociais causados pela globalização. Assim escreve Pace:

Em termos estritamente sociológicos tudo isso tem um nome. Chama-se processo de libertação religiosa: afastamento dos crentes das religiões institucionais ou frágil pertencimento (e identidade) do indivíduo às instituições religiosas de origem. ${ }^{9}$

Por outro lado, essa desejada libertação religiosa pode causar perda de identidade, de privacidade ou da liberdade pessoal. Consequentemente, sociedades com fortes tradições religiosas que determinam a convivência, a cultura e, até mesmo, seu sistema econômico, ao travar contato com diferentes povos, costumes e tradições religiosas e com essa "libertação", tendem a se retrair e perder sua referência, sentindo uma ameaça às suas famílias e ao seu povo. Esse medo, essa falta de compreensão e sentimento de estar sendo oprimido por uma cultura diferente da sua pode levar a uma negação de qualquer tipo de negociação e consequentemente, esses grupos tendem a se tornar fechados e até mesmo agressivos, como forma de manter sua estrutura social, e combater o que julgam ser prejudicial à sua tradição e seus costumes. ${ }^{10}$

Uma grande parcela dessa população que se sente ameaçada pela diversidade de opiniões e costumes muitas vezes contrários à sua cultura procura um mundo sem questionamentos, onde possam se sentir seguros, em comunidades que lhes pareçam mais estáveis. Comunidades mais flexíveis ou permissivas representam uma ameaça e oferecem resistência entre os fiéis mais conservadores. A reação a isso é o fundamentalismo, que traz certezas e um relativo conforto. Para esses fundamentalistas, os outros "representam uma séria ameaça à certeza conquistada a duras penas; eles devem ser convertidos, segregados ou, no extremo, expulsos ou 'liquidados ".. ${ }^{11}$

\footnotetext{
${ }^{9}$ PACE, E., Religião e Globalização, p. 34.

${ }^{10}$ ZIZEK, S., Violence, p. 142.

${ }^{11}$ BERGER, P. L; ZIJDERVELD, A., Em favor da Dúvida, p. 66.
} 
Uma consequência desse combate muitas vezes violento ao que os fundamentalistas entendem como ameaça aos seus costumes são conflitos que podem atingir uma parcela significativa de suas comunidades.

Assim, conflitos em sua própria terra, por motivos políticos ou religiosos, deslocam massas enormes de pessoas em busca de sobrevivência em terras com outros valores sociais, gerando dificuldades de adaptação, tanto ao migrante quanto à sociedade que o recebe.

A adaptação a uma nova cultura é e sempre foi difícil, principalmente para as primeiras gerações, criadas dentro de uma visão de mundo determinada pelas tradições de seus antepassados. Desta forma, é comum que se criem pequenas sociedades com usos e costumes em comum, alheias, inclusive, às leis locais, fato que impede uma sadia convivência entre povos de culturas diferentes, embora vivendo no mesmo espaço, sob as mesmas leis e costumes. Também os países que recebem esses migrantes, como resposta, podem se fechar em suas culturas e tradições e não serem receptivos, resultando em conflitos de ambos os lados.

Além da não aceitação de novos costumes, essa recepção, em alguns países, tende a formar comunidades marginais, trazendo como consequência desemprego, pobreza e fome.

\section{A Igreja Católica, a modernidade e a globalização}

Qual o papel da Igreja Católica frente a essa perda de identidade e relativização causada pela globalização?

A Igreja Católica Apostólica Romana sempre se pretendeu global, atribuindo-se a missão de alcançar todos os povos do mundo, seguindo o que é dito em Mc 16, 15 "E disse-lhes: ide pelo mundo, pregai o Evangelho a toda criatura" e também em Mt 28,19: "Portanto ide, fazei discípulos todas as nações, batizando-os em nome do Pai, do Filho e do Espírito Santo". Esses dois pequenos versículos determinaram a forma de agir dos cristãos desde o início do cristianismo. Por toda a Idade Média e Renascimento, os braços da Igreja envolveram toda a Europa e seu poder esteve ligado ao poder secular, quando não a ele submetido. Contudo, após os séculos XV e XVI a influência da Igreja Católica no mundo começou a declinar e acreditou-se que, após o Iluminismo, esmoreceria. Surpreendentemente, a partir do final do século XIX, o alcance das mensagens da Igreja por intermédio dos papas, cresceu como nunca antes na história do cristianismo. E não pela divulgação do próprio Vaticano, mas pela mídia ao redor do mundo. 
Em 1891, Leão XIII, preocupado com o desemprego e a miséria dos trabalhadores causada pela Revolução Industrial, publica a encíclica Rerum Novarum, criticando a falta de valores morais e éticos em uma sociedade cada vez mais distante de Deus e com uma economia que promovia uma distribuição de riqueza somente a uma pequena parte da população, enquanto os trabalhadores, que eram a maioria, viviam na miséria. Desta encíclica, passando pela Quadragesimo Anno (1931), de Pio XI, Mater et Magistra (1961) e Pacem in Terris (1963) de João XXIII, Populorum Proggressio (1967) e Octagesima Adveniens (1971) de Paulo VI, Laborem Exercems (1981) e Centesimum Annum (1991) de João Paulo II, Deus Caritas Est (2005) e Caritas in Veritate (2009) de Bento XVI, até a encíclica Laudato Si' (2015) de Francisco, a Igreja se mostra atenta às mudanças sociais e, desenvolvendo uma doutrina social, procura promover a dignidade da pessoa humana. Essas encíclicas foram destinadas não só aos católicos, mas a todos os povos, a toda a humanidade.

Porém, deve-se salientar que nem sempre a Igreja Católica se pretendeu moderna e em concordância com os avanços sociais. No final do século XIX o Papa Pio X se colocou contra o modernismo, que acreditava ser prejudicial e contrário ao catolicismo de então. $\mathrm{O}$ movimento modernista tinha como característica relativizar normas de dogma e fé. Assim afirma Martina:

Difundiam-se, portanto, nos ambientes católicos do início do século, um sentimento de mal-estar, uma ânsia de atualização, que apresentava todo um amplo leque de atitudes, ligadas entre si quando muito por um estímulo psicológico facilmente compreensível, não por um verdadeiro nexo intrínseco objetivo: do genérico reformismo do tipo rosminiano se passava a um movimento social, a uma exigência de renovação dos estudos, sobretudo positivos, para acabar depois numa tentativa de dar novas bases a todo o cristianismo. Esta última tendência, ainda que animada pela ansiedade de salvar a Igreja do isolamento e da superação, abria o caminho ao subjetivismo, desvalorizava o caráter sobrenatural do catolicismo, esvaziando-o de sua essência. Tratava-se, portanto, de tendências diferentes, que deveriam ser avaliadas caso a caso, que é difícil reunir sob uma denominação comum, não só pela dificuldade própria de toda síntese, mas sobretudo porque, como afirmou um dos expoentes do movimento, Ernesto Buonaiuti, "O caráter distintivo foi a própria indeterminação do seu programa. De fato ele não se chocou com um ponto particular da disciplina oficial". Infelizmente, repetiu-se no início do século XX, com Pio X, o que acontecera em meados do século anterior, com Pio IX: a cúria romana, até mesmo pelo caráter dos dois papas, não soube ou não quis distinguir os diversos aspectos, não separou 
os extremismos das posições moderadas, quem cria no transcendente e quem nutria dúvidas ou tinha perdido a fé, mas condenou em bloco as exigências da base. $\mathrm{O}$ problema, asfixiado e não resolvido, devia reaparecer, talvez com maior violência, em nossos dias. ${ }^{12}$

Ernesto Buonaiuti, professor de História da Igreja no seminário de Appolinaire, afirmou em sua obra Programa dos Modernistas (1908) que o método histórico crítico poderia revolucionar a teologia cristã. ${ }^{13}$ Incomodado, Pio X elabora seu descontentamento em sua Encíclica Pascendi Gregis. Sobre isso escreve O’Malley:

O papa apresentou uma síntese dos ensinamentos dos modernistas na qual descreveu a heresia como baseada em dois falsos princípios: a rejeição da razão metafísica, que levou ao ceticismo a respeito das provas racionais da existência de Deus; e a rejeição do sobrenatural, que levou à ideia de que a doutrina derivava unicamente da experiência religiosa. $\mathrm{O}$ assunto era extraordinariamente grave, disse Pio, porque os "fautores do erro" não deviam ser procurados entre inimigos, mas "no próprio seio da Igreja". Por essa razão eles eram "os mais perigosos inimigos da Igreja". ${ }^{14}$

Muitos historiadores viriam a afirmar que o pontificado de Pio $\mathrm{X}$ foi marcado pela defesa da fé católica, contra o perigo do modernismo.

Contudo, sobretudo depois da segunda Grande Guerra, a Igreja Católica Apostólica Romana deixou de se preocupar com o modernismo e se propôs a ser a mediadora entre conflitos que pudessem resultar em guerras ou em desrespeito aos direitos humanos. Sua voz novamente passou a ser ouvida e respeitada pelo mundo, de maneira que o número de países que estabeleciam relações diplomáticas no início do século XX, que era de algumas dezenas, passou a 182 países no ano de 2017.

João XXIII com a Encíclica Mater et Magistra, publicada em 15 de maio de 1961, se propõe a dar uma resposta aos problemas sociais da época, tendo em vista não apenas os movimentos sociais, mas econômicos, culturais, trabalhistas e outros. O documento, tratando da socialização, afirma:

A socialização é um dos aspectos característicos da nossa época. Consiste na multiplicação progressiva das relações dentro da convivência social,

\footnotetext{
${ }^{12}$ MARTINA, G. História da Igreja de Lutero a nossos dias, p. 79-80.

${ }^{13}$ MARTINA, G. História da Igreja de Lutero a nossos dias, p. 88-89.

${ }^{14}$ O'MALLEY, J.W., O que aconteceu no Vaticano II, p. 81.
} 
e comporta a associação de várias formas de vida e de atividade, e a criação de instituições jurídicas. O fato deve-se a multíplices causas históricas, como aos progressos científicos e técnicos, à maior eficiência produtiva e ao aumento do nível de vida. A socialização é simultaneamente efeito e causa de uma crescente intervenção dos poderes públicos, mesmo nos domínios mais delicados, como os da saúde, da instrução e educação das novas gerações, da orientação profissional, dos métodos de recuperação e readaptação dos indivíduos de algum modo menos dotados. Mas é também fruto e expressão de uma tendência natural, quase irreprimível, dos seres humanos: tendência a associarem-se para fins que ultrapassam as capacidades e os meios de que podem dispor os indivíduos em particular. Esta tendência deu origem, sobretudo nestes últimos decênios, a grande variedade de grupos, movimentos, associações e instituições, com finalidades econômicas, culturais, sociais, desportivas, recreativas, profissionais e políticas, tanto nos diversos países como no plano mundial. ${ }^{15}$

Pode-se dizer que essa Encíclica, escrita durante o complicado período da guerra fria, atenta aos problemas sociais de todos os povos, se torna um documento fundamental para a doutrina social da Igreja e já percebe sinais nocivos da globalização.

Com o espírito tomado pelas mudanças que já vinham ocorrendo desde o início da segunda grande guerra, tanto na sociedade, quanto dentro da Igreja, e preocupado com a atualização e maior inserção da Igreja no mundo, sempre atento aos sinais dos tempos, João XXIII convoca o Concílio Vaticano II, que deu novo rumo para a posição da Igreja Católica frente à sociedade global.

O Concílio Vaticano II, realizado entre 1962 e 1965, foi convocado com o intuito de confirmar o processo de aggiornamento para a modernidade, que já era sentido em toda a Europa. A partir do Concílio, a Igreja Católica apresentou uma mudança inesperada em relação à modernidade e à globalização. Em sua constituição pastoral Gaudim et Spes, promulgada em 7 de dezembro de 1965, que trata da inserção da Igreja no mundo contemporâneo, com seus aspectos doutrinários e pastorais, afirma:

Depois de ter exposto a dignidade da pessoa humana, bem como a missão individual e social que está chamada a realizar no mundo, o Concílio dirige agora a atenção de todos, à luz do Evangelho e da experiência humana, para algumas necessidades mais urgentes do nosso tempo, que profundamente afetam a humanidade. Entre as muitas questões que hoje

${ }^{15}$ MM 59-60. 
a todos preocupam, importa relevar particularmente as seguintes: o matrimônio e a família, a cultura humana, a vida económico-social e política, a comunidade internacional e a paz. Sobre cada uma delas devem resplandecer os princípios e as luzes que provêm de Cristo e que dirigirão os cristãos e iluminarão todos os homens na busca da solução para tantos e tão complexos problemas. ${ }^{16}$

Essa constituição pastoral insere a Igreja Católica no mundo atual, com suas diversidades e problemas não só de cunho religioso, mas, principalmente, econômico e social. Propõe também que a Igreja não se resume somente ao clero, mas a todo o povo de Deus alcançando assim todas as regiões do mundo.

Após o Concílio, o papado assumiu definitivamente o papel de porta-voz dos direitos humanos e da defesa da dignidade da pessoa humana, aceitando também a liberdade religiosa e diferenças culturais, não mais se resumindo a uma postura centralizadora romana. Com isso, passou a obter o respeito não somente da comunidade católica. Sua representação na cúria também não mais se reservou a uma maioria europeia e italiana, mas de outros continentes, principalmente da África e América do Sul.

O papado, assumindo sua autoridade universal, não como na Idade Média, mas distante do poder secular e admitindo a liberdade religiosa e de pensamento, apresenta-se como poderosa competidora pela religiosidade global com vantagem de recursos humanos e materiais e falando uma linguagem comum a todos os seres humanos. A partir de João Paulo II os papas têm tentado globalizar sua imagem com incessantes viagens pelo mundo e se encontrando com diversas lideranças civis e religiosas, sempre em tom respeitador e conciliador, levando sua mensagem a católicos e não católicos ao redor do mundo.

Preocupada também com a miséria causada pela economia mundial e com os conflitos sociais que têm deslocado milhares de refugiados, a Igreja Católica tem se comprometido com o seu bem-estar, seu acolhimento e auxílio não só espiritual, mas também material, condenando políticas econômicas que tem levado grandes regiões do planeta à miséria.

Desta maneira, mesmo com sede ainda em Roma e com o Papa como principal figura e líder, a Igreja Católica tem influenciado de maneira eficiente a opinião pública e atraído a atenção da mídia transnacional, deixando para trás a imagem negativa da era medieval e seu caráter regional, trazendo para si a imagem de uma Igreja globalizada e atualizada à modernidade.

${ }^{16}$ GS 46. 


\section{Conclusão}

A modernidade e a globalização, colocando em contato pessoas de todo o mundo, formando uma aldeia global, sem fronteiras mercadológicas, tem como efeito colateral, conflito financeiro, social e religioso. O medo do desconhecido dificulta a aproximação e a compreensão do outro, causando distância social e recusa em aceitar comportamentos e regras diferentes. A saída encontrada, mercantilizar as religiões, desprezando características locais e forjando características em comum, que, em geral, não fazem parte de nenhuma tradição específica, parece não ser a resposta. Assim, como também não é uma resposta eliminar a cultura e as tradições religiosas procurando o bem-estar social em experimentos sociais ideológicos, políticos ou financeiros. Eliminar as tradições de um povo mais traz severos problemas do que benefícios, afinal, essas tradições moldaram sociedades e determinaram comportamentos.

Existe uma Teologia que dê conta de resolver o problema da globalização e das incertezas causadas pelas diferentes propostas de organização social, familiar e religiosa? A resposta é não! Pois não há uma só sociedade mundial, há pluralidade de tradições, aspirações e costumes e isso deve ser aceito e respeitado.

Contudo, a Igreja Católica tem procurado, nos campos social e religioso, pontos em comum entre suas crenças sociais e códigos de conduta. Dessa maneira, sua influência e importância no cenário global tem crescido de maneira substancial, sendo aceita como mensageira da paz, dos direitos humanos e como uma igreja mundial, acessível a todos os povos e culturas.

\section{Referências bibliográficas}

BAUMAN, Z. Modernidade e ambivalência. Rio de Janeiro: Jorge Zahar, 1991. BAUMAN, Z. O Mal-estar da Pós-modernidade. Rio de Janeiro: Jorge Zahar, 1997.

BERGER, P. L, O dossel sagrado: elementos para uma teoria sociológica da religião. São Paulo: Paulinas, 1985.

BERGER, P. L., Os Múltiplos Altares da Modernidade. Rumo a um Paradigma da Religião Numa Época Pluralista. Petrópolis: Vozes, 2017.

BERGER, P. L.\& ZIJDERVELD, A., Em favor da dúvida. Como ter convicções sem se tornar um fanático. Rio de Janeiro: Elsevier, 2012.

BÍBLIA de Jerusalém. Nova ed. rev. e ampl. 2. impr. São Paulo: Paulus, 2002. 
CONCÍLIO VATICANO II. Constituição Pastoral Gaudium et Spes. Disponível em <http://www.vatican.va/archive/hist_councils/ii_vatican_council/documents/vatii_const_19651207_gaudium-et-spes_po.html $>$ Acesso em: 15 ago. 2018.

CONCÍLIO VATICANO II. Constituição Pastoral Lumen Gentium. Disponível em: <http://www.vatican.va/archive/hist councils/ii_vatican_council/documents/vatii_const_19651207_gaudium-et-spes_po.html $>$ Acesso em: 13 ago. 2018.

GIDDENS, A. As Consequências da Modernidade. São Paulo: Editora UNESP, 1991.

GOERGEN, P. Pós-modernidade, ética e educação. Campinas: Autores Associados, 2005.

JOÃO XXIII, PP. Carta Encíclica Mater et Magistra. Disponível em: $<$ http://w2.vatican.va/content/john-xxiii/pt/encyclicals/documents/hf_jxxiii_enc_15051961_mater.html>. Acesso em: 13 ago. 2018.

LIBANIO, J. B. Globalização e impacto sobre a fé. Disponível em: $<$ http://www.celam.org/documentacion/172.doc>. Acesso em: 05 ago. 2018.

MARTINA, G. História da Igreja de Lutero a nossos dias. A era contemporânea. São Paulo, Edições Loyola, 2014. v.IV-A.

O’MALLEY, J. O que aconteceu no Vaticano II. São Paulo, Edições Loyola, 2014. PACE, E. Religião e Globalização. In: ORO, A. P.; STEIL, C. A. (Orgs.). Globalização e Religião. Petrópolis: Vozes, 1997.

PRANDI, R. A Religião e o Planeta Global. In: ORO, A. P.; STEIL, C. A. (Orgs.): Religião e Globalização. Petrópolis: Editora Vozes, 1999. p. 70.

ZIZEK, S. Violence. New York: Picador, 2008.

Marcelo Amaral Lanfranchi Mestre em Teologia pela Pontifícia Universidade Católica de São Paulo

São Paulo / SP - Brasil E-mail: malanfranchi@yahoo.com.br 